\title{
Comparison of Toxin Fractions Isolated from Protoscoleces and Hydatid Cyst Fluid of Hydatid Cyst of Sheep in Mosul, Iraq
}

\author{
Najah S. Al-Omar \\ Department of Biology \\ College of Science \\ University of Mosul
}

(Received 20/6/2012 ; Accepted 26/11/2012)

\begin{abstract}
Pooled protoscoleces and hydatid fluids were collected from different sheep livers, and compared with protoscoleces and hydatid fluid from liver of one sheep. Toxin fraction of protoscoleces (P) and hydatid cyst fluid were isolated from hydatid cyst of sheep origin. Chloroform-methanol soluble fractions (CMSFs) were separated by thin layer chromatography (TLC) on silica gel G 60 (Riedel-deHean) coated plate $(20 X 20 \mathrm{~cm})$ on mixture of hexane:diethyl ether:formic acid (80:20:2 v/v/v). CMSFs were identified by TLC separation, ultra-violet light (254 nm) and by iodine evaporation under visible light.

the separation of toxin fractions (TFs) and hydatid cyst fluid (HCF), from different batches of liver protoscoleces and HCF, on TLC, indicate the existence of some differences in the number and rate flow of the TFs between protoscoleces and cyst fluid of the same host and between protoscoleces obtained from cysts of different sheep, the same was obtained in case of HCF of different sheep hosts.
\end{abstract}

Keywords: Toxin Fraction, Protoscoleces, Hydatid Cyst, Echinococcus.

مقارية الأجزاء للسامة المعزولة من الرؤبست الأولية وسل الهيس العري.من أكيلسمائية لأغنلمفي الموطل / المقول

\section{الملغص}

جمعت الرؤيست الأولية وللسوالل العدرية من لكباد اغنلم مختلفة وقورنت مع رؤيست أولية وال سالي

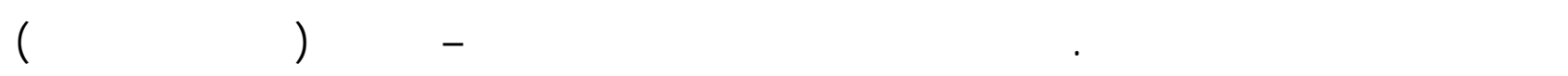

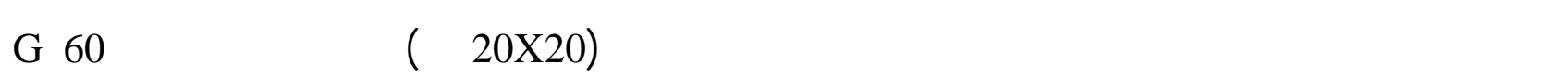

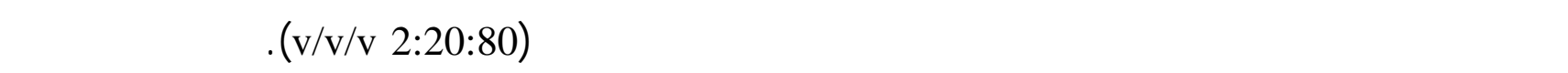

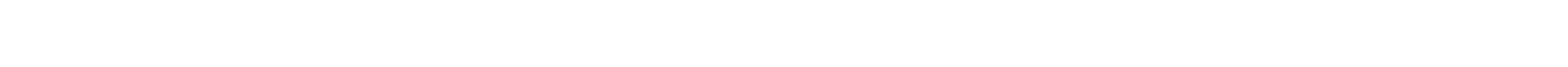
الضوء المرئي. 
فصلت الأجزاء للسلمة، وم الحصول عليها من حزملت مختلفة من الرؤيست الأولية للكبد ولس الال

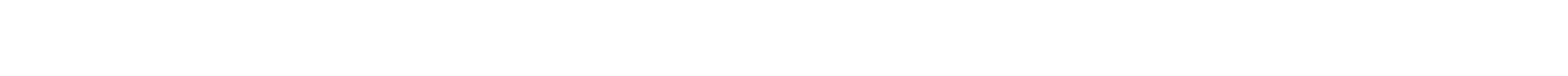

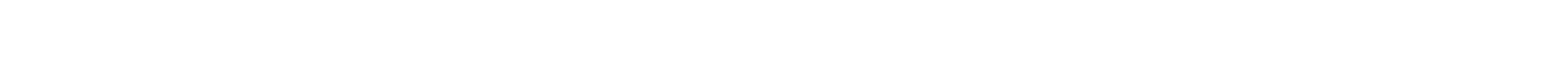

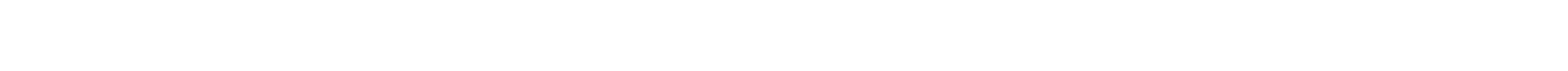
للسائل الكيس العدري لمضائف الأغنلم المختلفة.

\section{INTRODUCTION}

Cystic echinococcosis is a cyclozoonotic disease of global importance (Andersen et al.,1997), caused by the larval stage of the taeniid tapworm Echinococcus granulosus. These cestodes, like other parasites, develop and survive in an environment which is often hostile to them. Facing aggressive conditions, they have to use various and complex strategies to seclude from such environment (Camus et al., 1995). It has been suggested that the hydatid cyst can actively defend itself employing a mechanism based on the cytotoxicity of the hydatid fluid (Janssen et al., 1997). Such effect has been described versus lymphocytes (Annen et al., 1981), macrophages (Osuna et al., 1987). Yet, the fact that mice, infected with Echincoccus granulosus, develop an acquired immunity, is not suggestive of a model in which hydatid cyst provoke a general and persistent immunosuppression of the host (Janssen et al., 1997). Some of these mechanisms can take the form of immunomodualtion of the host immunity (Lyod and Soulsby, 1988). However, observations of secondary hydatidosis have shown that the establishment of hydatid cysts depends on the effect of cyst fluid toxin fractions on host immune response in order to creat some kind of the immunohomeostasis between the parasites and the host (De Ryck et al., 1991).

Osuna et al., (1985) found that there are certain substances, secreted by the germinal layer of cyst, which possess cytotoxic effect on certain cells of the host, their main targets are the macrophages and they have been found to be lipid in nature (Osuna et al., 1987). These fractions, treated as "toxin fractions (TFs)", have been found to differ in their effect on the host cells according to the host they are obtained from. Salih and Abbu (2001) demonstrated that these fractions are strain-specific and they are not cytotoxic to macrophages only but to microphages as well (Salih and Abbu, 2002).

The present study is a continuation to the above mentioned results in which TFs were isolated from protoscoleces (P) and hydatid cyst fluid (HCF) of Echinococcuss granulosus of sheep origin with an ultimate goal of investigating the possibility of existence of some differences in the TFs of these materials isolated from same host but from different batches obtained from more than only one host. The above mentioned demonstrations motivated us to investigate the effect of TFs isolated from HCF and P of hydatid cysts of sheep origin as possible immunmodulators in mice prior to infection with secondary hydatid cyst. 


\section{MATERIALS AND METHODS}

\section{Sourse of hydatid cysts}

Hydatid cysts of sheep origin were obtained from infected livers of slaughtered sheep in Nineveh slaughter House.

\section{Isolation of cyst fluid and protoscoleces}

Protoscoleces were collected aseptically from the cyst according to (Smyth, 1985). Viability was estimated according to (Smyth and Barrett, 1980) and only cysts with viability rate of more than $90 \%$ were used after centrifugation at $7600 \mathrm{~g}$ (10000 rpm), using a Cryofuge 4-6 (Heareus) for 10 minutes at $4 \mathrm{C}^{0}$, the supernatant HCF was separated and kept in sterile containers in a refrigerator at $20 \mathrm{C}^{0}$ until used.

\section{Separation of prtoscoleces and cyst fluid toxin fractions}

Cyst fluid fractions (CFFs) were separated according to (Janssen et al., 1997). Ammonium sulfate was added $(49.35 \mathrm{gm} / 100 \mathrm{ml})$ to the cyst fluid and supernatant of homogenated protoscoleces each one alone (protoscoleces were suspended with PBS (1:4 $\mathrm{v} / \mathrm{v}$ ), then freezed and thawed two times prior homogenization with an ultra sonicator at 24 waves for 3-6 minutes. Finally, the liquid was centrifuged at $14000 \mathrm{rpm}$ for 50 minutes to separate the supernatant and the fluid was left in the refrigerator at $4 \mathrm{C}^{0}$ for 24 hrs to give enough time for the precipitation of protein. The fluid was centrifuged at 37000g (22150 rpm) for 30 minutes at $4 \mathrm{C}^{0}$. Protoscoleces of different cyst collected from livers of different sheep were mixed together forming one batch .

An equal volume of chloroform was added to the supernatants. Two layers were formed after centrifugation. The chloroform layer was separated and half volume of methanol (chloroform: methanol $=2: 1, \mathrm{v} / \mathrm{v}$ ) was added and centrifuged under the same conditions mentioned above. The supernatant was dried by rotary evaporator. The chloroform-methanol soluble fractions (CMSFs), or TFs were kept in refrigerator and -20C ${ }^{0}$ until used. At use, they were dissolved in few drops of chloroform and completed by phosphate buffer saline (PBS).

\section{Separation of toxin fractions by thin layer chromatography (TLC)}

Chloroform-Methanol soluble fractions (CMSFs) were separated by thin layer chromatography (TLC) on silica gel G60 (Riedel-deHean) coated plates $(20 \mathrm{X} 20 \mathrm{~cm})$ on mixture of hexane: diethylether: formic acid (80:20:2 v/v/v). TLC separated CMSFs were identified under ultra-violet light $(254 \mathrm{~nm})$ and by iodine vapors under visible light (Kirchner, 1978 ; Janssen et al., 1997).

\section{RESULTS}

The separation of TFs and HCF by TLC from different batches of liver protoscoleces and HCF of sheep origin indicate the existence of some differences in the number and rate flow of the TFs between protoscoleces and cyst fluid of same host and between protoscoleces obtained from cysts of different sheep, the same was obtained in case of HCF of different sheep host Table (1), Fig. (1). 


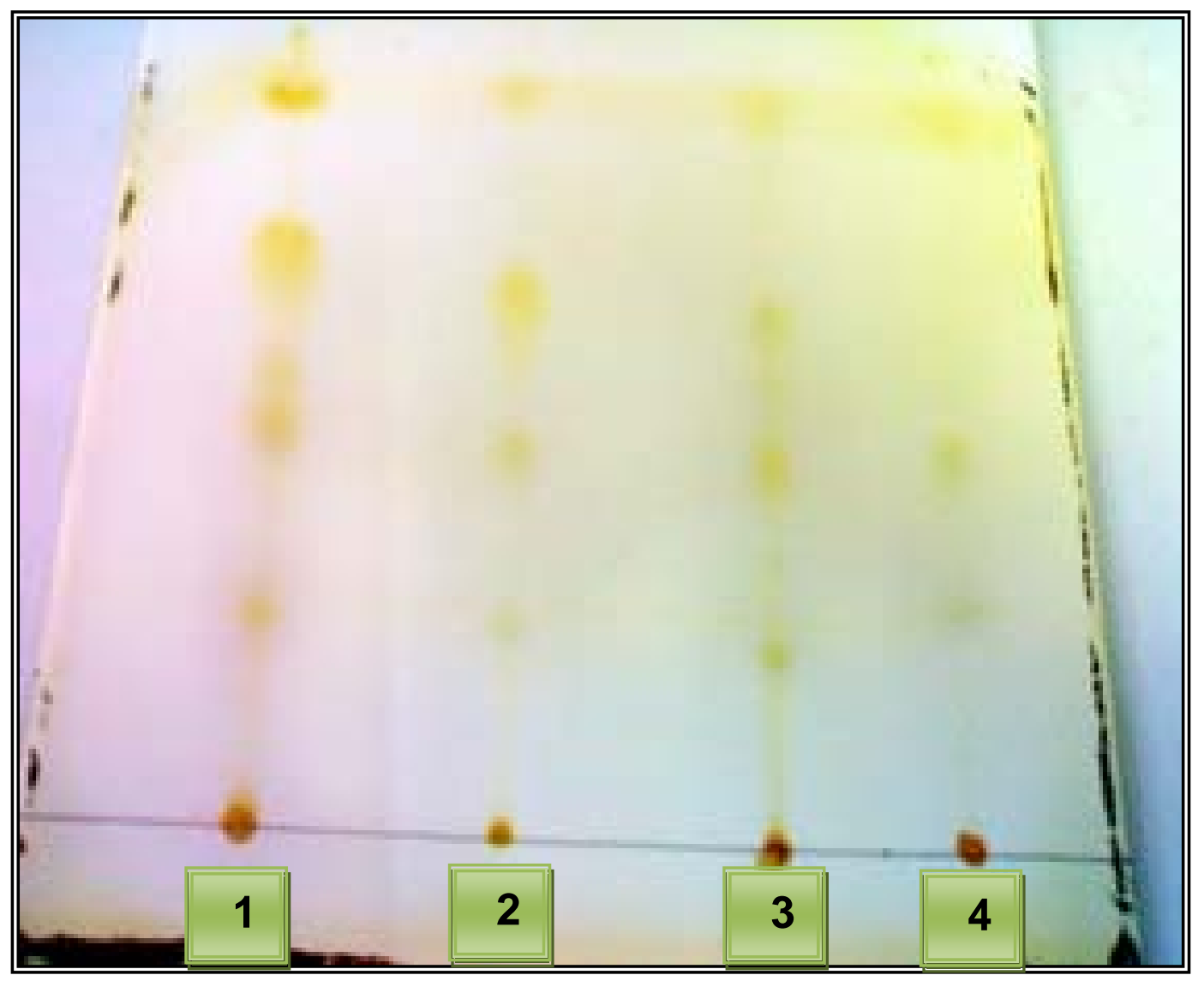

Fig. 1: Photograph of TLC showing a number of toxin fractions isolated from protoscoleces ( 1 and 2$)$ and hydatid cyst fluid ( 3 and 4$)$ of sheep origin under U. V. light ( $254 \mathrm{~nm}), 1$ and $3=$ pooling, 2 and $4=$ one liver.

Table 1: Number and rate of flow of toxin fractions isolated from liver protoscoleces and hydatid cyst fluid of sheep origin separated by thin-layer chromatography technique.

\begin{tabular}{|c|c|c|c|}
\hline \multicolumn{2}{|c|}{ Sourse of TFs* } & No. TFs & Rate of flow (RF) \\
\hline \multirow{9}{*}{$\begin{array}{l}\text { Toxin Fractions } \\
\text { (Protoscoleces) }\end{array}$} & \multirow{5}{*}{1} & 1 & 0.225 \\
\hline & & 2 & 0.415 \\
\hline & & 3 & 0.461 \\
\hline & & 4 & 0.580 \\
\hline & & 5 & 0.743 \\
\hline & \multirow[t]{4}{*}{2} & 1 & 0.230 \\
\hline & & 2 & 0.410 \\
\hline & & 3 & 0.564 \\
\hline & & 4 & 0.764 \\
\hline \multirow{7}{*}{$\begin{array}{l}\text { Toxin Fractions } \\
\text { Cyst fluid }\end{array}$} & \multirow[t]{3}{*}{3} & 1 & 0.205 \\
\hline & & 2 & 0.394 \\
\hline & & 3 & 0.553 \\
\hline & \multirow[t]{4}{*}{4} & 4 & 0.743 \\
\hline & & 1 & 0.246 \\
\hline & & 2 & 0.435 \\
\hline & & 3 & 0.743 \\
\hline
\end{tabular}

*1 and $3=$ pooling , 2 and $4=$ one liver 


\section{DISCUSSION}

The result of the current study showed that there were differences in number and type of toxin fractions that were isolated from protoscoleces of the same host and those between different hosts. The same thing for hydatid cyst fluid has been obtained from the same host and different hosts whene numbers and types of toxin fractions were different, this is completely as Salih et al., (2009) refer to. They clarify that causes return to differences in the degree of metabolislm level, that toxin fractions of hydatid fluid are metabolic products, while TFs of $\mathrm{P}$ are non- metabolic.

In this field too, Stanley and Mauahan (2003) pointed to the metabolism of TFs which play a role in changing the toxic degree of some TFs, and this can support that there were differences in the degree of toxicity of TFs of P and HCF, and this is noted in the differences of differential count of blood picture.

The possibility that TFs of HCF might be produced by analysis of dead of immature $\mathrm{P}$ in HCF which leads to the presence of various nature compounds to its opposite of mature $\mathrm{P}$ (Al-Omar, 2009).

The differences that emerged between $\mathrm{P}$ and HCF, collected from different $\mathrm{P}$ and HCF, which were collected from different sheep may be caused by collection of P and HCF as batches and got one treatment. Otherwise $\mathrm{P}$ of different development stages were collected so as for HCF may have contained of $\mathrm{P}$ at various stages of degeneration.

It should be noted that AL-jawady (2009) pointed the possibile infection of sheep with more than strain of E. granulosus may cause mixing more than strain of E. granulosus, which lead to the emergence of such differences.

\section{REFERENCES}

Aljawady, M. A. (2009). Sheep can be infected with more than one strain of Echinococcus granulosus. J. Anim. Vet. Adv., 8 (11), 2177-2180.

Al-Omar, N.S. (2009). Effect of toxin fraction isolated from protoscoleces and hydatid cyst fluid of sheep origin on blood picture in mice. Tik. J. Pur Sci., 16(1), 208-2011.

Andersen, F.L; Ouhelli, H. ; Kachani, M. (1997). Compendium on cystic Echinococcosis in Africa and in Middle Eastern Countries with special reference to Morocco; Brigham young University print services Provo, 1-17.

Annen, J.M; Mohler, P; Eckert, M. (1981). Cytotoxicity of Echinococcus granulosus cyst fluid in vitro . Parasitenkd. 65,79-88.

Camus, D.; Zali. M.G.; Vannier, M. A.; Banic, D.M. (1995). The art of parasite survival. Braz, J. Med. Bio. Res., 28, 399-413.

De Ryck, P.H.; Janssen, D.; Osuna, A; Lazuim, J. (1991). The immunohomeostatic role of hydatid cyst toxins (Echinococcus granulosus). Parasitol. 33,55-60.

Janssen, D.; Rueda, M.C.; De Ryck PH and Osuna, A. (1997). Immunomodulation by hydatid cysts fluid toxin (Echinococcus granulosus). Parasit. Immunol., 19,149160.

Kirchner, J.G. (1978). "Thin-Layer Chromatography". Arnold weissberger (Ed.) v 14p 1137 U.S.A.

Lyod, S.; Soulsby, E.J.L. (1988). "Immunological Responses of the Host". In: MehILorn H (Ed) Parasitology in Focus. Springer-Verlag. Berlin. pp.619-650. 
Osuna, A.; Gamarro, F.; Janssen, D. ; Carreras, M.A.; Castanys, S.; Adroher, F.J.; DeRyck, P.H. (1987). Cytotoxicity of Echinococcus garnulosus hydatid cyst fluid: specific activity and biochemical characterization. Rev. Ibr. Parasitol., 47,47-52.

Osuna, A.; nGammaro, F.; Janssen, D.; Carreras, M.A.; Castanys, S.; De Ryck, P.H. (1985). Echinococcus granulosus: cytotoxic effect of hydatid cyst fluid on intermediate host cells. (Parasito. Protozoo. Bruss.,) 81 A.

Salih, N.E; Abbu, O.A.N, (2001). Strain specifity in toxin fraction from hydatid cyst fluid of different host origin. Riv. Parassitol., 18(62)-3, 213-219.

Salih, N.E.; Abbu, O.A.N. (2002). Phagocytosis in mice treated with hydatid cyst fluid of human, sheep, cattle origin it is toxin fractions. Riv. Parassitol., 19, 63.

Salih, N.E.; Al-Omar, N.S.; Abdullah, I.T. (2009). Effect of toxin fraction isolated from protoscoleces and hydatid cyst fluid of sheep origin on phagocytosis in BALB/C mice. Tik. J. Pur. Sci., 15(2),208-2010.

Smyth, J.D.; Barrett, N.J. (1980). Procedures for testing the viability of human hydatid cyst following surgical removal specially after chemotherapy. Trans. Roy. Soc. Trop. Med. Hyg., 74,649-652.

Smyth, J.D. (1985). "In vivo Culture of Echinococcus ssp.". 13th Int. Cong. Hydatid. Madrid., pp.84-95.

Stanley, E. M. (2003). "Toxicological Chemistry and Biochemistry". 3rd ed. chapter 4. BocA Raton London New York Washington, D.C. 